\title{
AUTHORSHIP PATTERNS AND COLLABORATIVE RESEARCH OF ONCOLOGY RESEARCH OUTPUT IN INDIA: A SCIENTOMETRICS STUDY
}

\author{
Senthilkumar, $\mathbf{R}^{*}$. and M. Muthukrishnan \\ Head of Research Department of Library and Information Science, Kongunadu Arts and Science College, \\ Coimbatore - 641029. \\ *E.mail: kasclibrary@yahoo.com
}

\begin{abstract}
The paper analysis authorship patterns and collaborative research of oncology research in Indiaas reflected by the research papers listed in Web of Science database for a period of 11 years from 2005-2015. The increased trend towards multiple authorship is predominant as compare to single authorship in case of oncology in India.In the study, the degree of collaboration was not a constant value, it reveals varies of 0.03 to 0.16 percent and the mean quality as 0.09 . The analysis found that single author papers maintained a low profile among oncology research scientists and the multi authorship pattern is expanding slowly in Indian oncology research.
\end{abstract}

Keywords: Authorship pattern, Degree of collaboration, Time Series Analysis, Oncology, Scientometrics.

\section{INTRODUCTION}

One of the preeminent fundamental requirements for advancement in medical and scholarly vocations is the authorship of scientific papers.Collaborative authorship has been a trademark highlight of the present day medical science and there has been a predictable pattern towards expanded collaboration in all the branches of sciences. Multiple authorship and cooperation are among the most critical necessities of exploratory and innovative work today.

A percentage of the writings are evaluated by the authors before conducting the present study.By observing the authorship patterns to be measurably essentially connected with publication in high ranking journals. Consideration of professors, research scholars, and scientists as authors, specifically, were all emphatically connected with publication in high ranking journals.SudhierPillai,K G (2007) have describedThe study revealed that team research is predominant in journal articles while solo research is the trend in the case of books Elango and Rajendran (2012)briefed information that multi authored contributions are dominated in the field of marine sciences. Average collaboration rate (0.57) is better collaboration and mean number of authors per joint authored paper is 3.4. Andras Pinter (2013) examined the authorship patterns in the articles published in the Journal of Pediatric Surgery (JPS) and found that thepercentage of papers with less than 3 authors significantly declined, whereas those with 4 to 5 authors did not change. Manuscripts with more than 6 authors significantly increased. Pallab
Pradhan et al. (2013) studied the authorship Pattern and Degree of Collaboration in Indian Chemistry Literature. The study found that the researchers in chemistry are keen towards team research or group research rather than solo research.

Goyal et al. (2013) have analyzed the tendency in the direction of collaborative research is seen steady during 2002-2011 in the field of Chemical Sciences. Outcome of study clearly show that authorship trend is moving on the way to multiple authorship and degree of collaboration is found to be high.

Michael et al. (2014) examined the enrichment of co-authorship patterns with author scientific profiles helps uncover associations between author team characteristics and appearance in high-impact journals. Navaneethakrishnan (2014) the analysis revealed that the majority of the publications are contributed by multiple authors. Degree of collaboration was progressively increased over the study span. Neena Kapoor et al. (2014) has described the study demonstrates that the average number of authors per publication dramatically increased from 1980 to 2013 in major radiology journals. Chandran and Natarajan (2015) have briefed the highest number of contributions were multi authored papers. It is found that that the degree of collaboration ranges from 0.36 to 0.77 and the average degree of collaboration is 0.59(9). Mehmet Ali Koseoglu (2016) indicated, the authorship pattern of the SMJ shows multi- authored articles dominated solo work, and this domination increased over the past periods; however, the 
growth of multi- authored articles is limited to papers with two or three authors. Senthilkumar and Muthukrishnan (2016) the analysis revealed that the more research papers are being contributed under multiple authorship.

Here, the author has made an attempt to study the authorship pattern, collaborative researchand country of the corresponding author on oncology literature published during the period 2005- 2015 and indexed in web of science database.

\section{OBJECTIVES}

The objectives of the study are brief as follows:

$\checkmark \quad$ To study the year wise distribution of oncology research output in India.

$\checkmark \quad$ To study authorship pattern in oncology literature

$\checkmark \quad$ To study the year wise single and multiauthored Papers

$\checkmark \quad$ To study the degree of collaboration in the field of oncology

$\checkmark \quad$ To study the time series analysisin the field of oncology

\section{DATA ANALYSIS}

Data was downloaded on $02^{\text {nd }}$ May 2016 for a period of eleven years (2005-2015) from the Web of Science (WoS) of the Thomson Reuters, USA.The search keyword has 'oncology' has been used for the purpose of collection of data. The size of the sample downloaded for the purpose is 10574. The downloaded records was enriched with different parameters like authors, title, years, research institutions, document type and so on. Further the records analyzed by using Histcite and bibexcel software application.

Table 1. Year Wise Distribution of Publications

\begin{tabular}{cccc}
\hline S No & Year & Total Papers & \% \\
\hline 1. & 2005 & 349 & 3.30 \\
2. & 2006 & 397 & 3.75 \\
3. & 2007 & 580 & 5.49 \\
4. & 2008 & 592 & 5.60 \\
5. & 2009 & 813 & 7.69 \\
6. & 2010 & 978 & 9.25 \\
7. & 2011 & 1080 & 10.21 \\
8. & 2012 & 1116 & 10.55 \\
9. & 2013 & 1276 & 12.07 \\
10. & 2014 & 1569 & 14.84 \\
11. & 2015 & 1824 & 17.25 \\
\hline \multicolumn{5}{r}{ Total } & 10574 & 100.00 \\
\hline
\end{tabular}

\section{Graph 1. Year Wise Distribution of Publications}

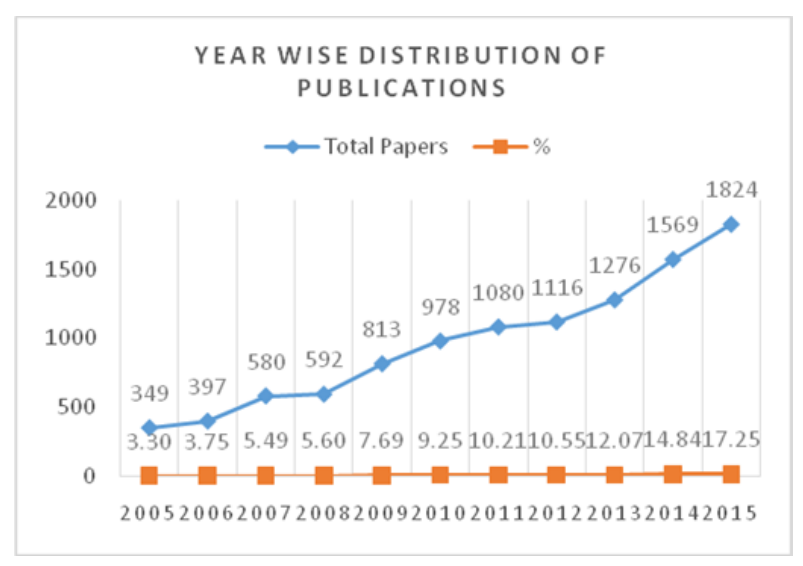

Here, an effort was made to analyzefor the period of eleven years from 2005-2015. Table-1 and Graph-1 present the year-wise distribution of number of publications indexed in WoS database.The average number of article publication was 961.27 articles per year.It has been realized a steady growth of Indian research output in oncology from 2005 onwards.In the study, the commitment of prior five years (2005-2010) was less than the average publications per year.Out of 10574 articles 1824 (17.25\%) articles were published in 2015 and 349 (3.30\%) articles were in 2005, which are highest and lowermost in eleven years respectively.

\section{AUTHORSHIP PATTERNS}

The below table 1 reveals that a total of 61207 authors have contributed the 10574 articles and the average number of authors per article observed to be 5.79. Among 10574 articles, 595(5.63\%) articles are written by single author and $9979(94.37 \%)$ articles are written by multiple authors.

Four authored articles involved highest percentage 1610 (15.23\%), after Five authored articles $1446(13.68 \%)$ of the aggregate 10574 articles and six to Twelve authored contributions are between 13 to 1 percent. Above Twelve authored contributions are below one percent of articles.

In this manner, showing unmistakably the increased trend towards multiple authorship is predominant as compare to single authorship in case of oncology in India. The above graph demonstrates that the diminishing patterns in the quantity of authors as far as group or team research with respect to more than six authors. 
Table 2. Presenting the authorship pattern in oncology research output.

\begin{tabular}{cccccc}
\hline S.No. & No. of Authors & No. of Publications & $\mathbf{\%}$ & Authorship pattern & $\mathbf{\%}$ \\
\hline 1. & Single & 595 & 5.63 & 595 & 0.97 \\
2. & Two & 1067 & 10.09 & 2134 & 3.49 \\
3. & Three & 1374 & 12.99 & 4122 & 6.73 \\
4. & Four & 1610 & 15.23 & 6440 & 10.52 \\
5. & Five & 1446 & 13.68 & 7230 & 11.81 \\
6. & Six & 1305 & 12.34 & 7830 & 12.79 \\
7. & Seven & 893 & 8.45 & 6251 & 10.21 \\
8. & Eight & 605 & 5.72 & 4840 & 7.91 \\
9. & Nine & 396 & 3.75 & 3564 & 5.82 \\
10. & Ten & 456 & 4.31 & 4560 & 7.45 \\
11. & Eleven & 202 & 1.91 & 2222 & 2.63 \\
12. & Twelve & 144 & 1.36 & 1728 & 1.95 \\
13. & Thirteen & 92 & 0.87 & 1196 & 1.62 \\
14. & Fourteen & 71 & 0.67 & 994 & 1.32 \\
15. & Fifteen & 54 & 0.51 & 810 & 0.84 \\
16. & Sixteen & 32 & 0.30 & 512 & 1.08 \\
17. & Seventeen & 39 & 0.37 & 663 & 0.82 \\
18. & Eighteen & 28 & 0.26 & 504 & 0.84 \\
19. & Nineteen & 27 & 0.26 & 513 & 6.08 \\
20. & Twenty & 39 & 0.37 & 780 & 100 \\
21. & Twenty+ & 99 & 0.94 & 3719 & 61207 \\
\hline
\end{tabular}

Graph 2. Presenting the authorship pattern in oncology research output

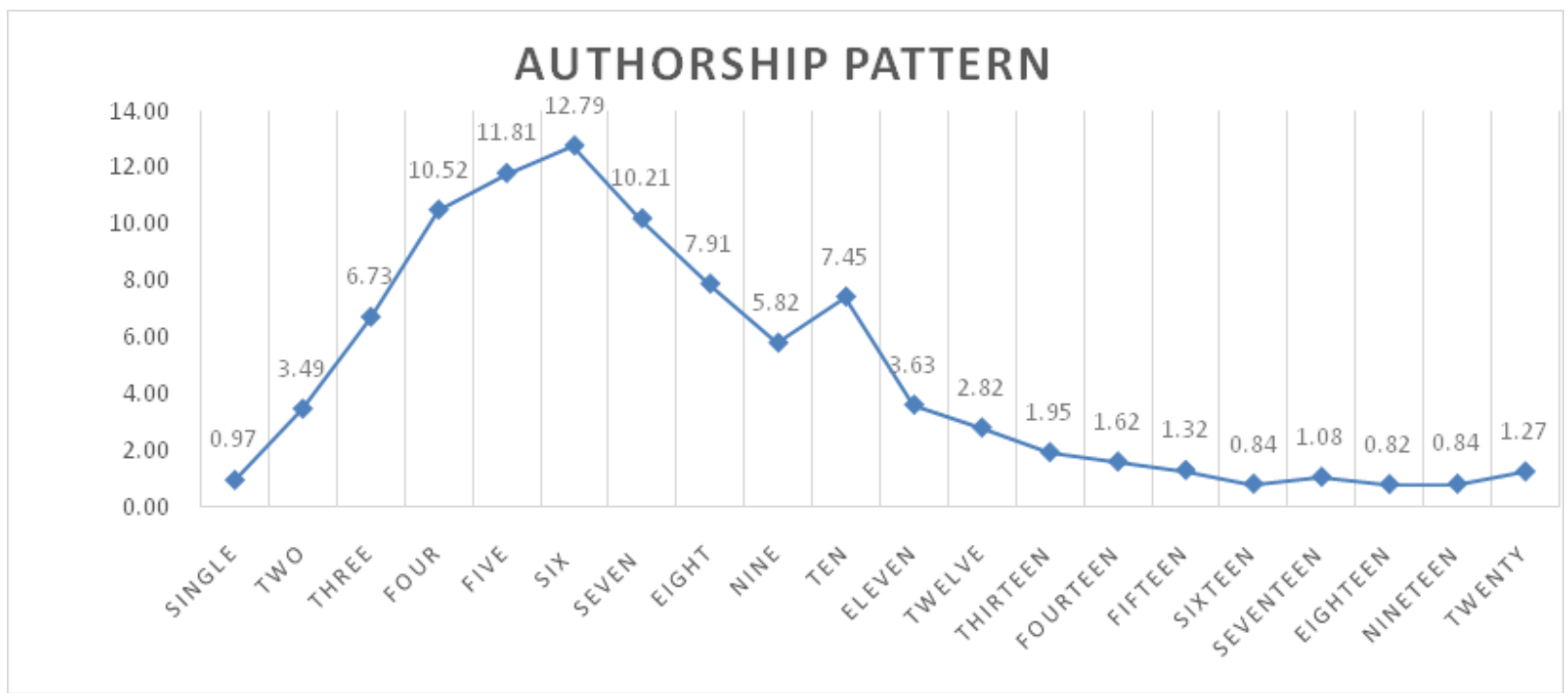

\section{DEGREE OF AUTHOR'S COLLABORATION}

The degree of collaboration varies from one discipline to another. It is generally high in the intensely collaborative scientific and technical fields, but low in the humanities. The formula given by $\mathrm{K}$ Subramanyam (Subramanyam, 1983) is useful for determining the degree of collaboration in quantitative terms. The mathematical deduction of the formula is

$C=\frac{N m}{N m+N s}$

Where, $\mathrm{C}=$ Degree of collaboration in a discipline

$\mathrm{Nm}=$ number of multi-authored papers in the discipline 
Ns $=$ number of single-authored papers in the discipline

Table 3. Degree of Collaboration

\begin{tabular}{ccccccc}
\hline S.No. & Year & $\begin{array}{c}\text { Single } \\
\text { Author }\end{array}$ & $\%$ & $\begin{array}{c}\text { Multi } \\
\text { Authors }\end{array}$ & \% & DC \\
\hline 1. & $\begin{array}{r}2005- \\
2015\end{array}$ & 595 & 5.63 & 9979 & 94.37 & 0.94 \\
\hline
\end{tabular}

Here, $\mathrm{Nm}=9979$

Ns $=595$

$C=\frac{9979}{9979+595}$

$=0.94$, Thus, the degree of collaboration (C) is 0.94

The analysis of Table -3 shows that the degree of collaboration during the period of 11 years (2005-2015) is 0.94. The single authored articles are covered only 595 (5.63\%) during the years. The multi authored articles 9979 (94.37\%) are maximumthroughout the years. which obviously shows its strength upon multi authored collaborative research.However, when we analysis the year-wise degree of collaboration for 11 years, the outcomes arise different.

The Table4 speaks to the year wise number of multiauthored articles and their degree ofcollaboration. In the study, the degree of collaboration was not a constant value, it reveals varies of 0.03 to 0.16 percent and the mean quality as 0.09.The analysis found that single author papers maintained a low profile among oncology research scientists and the multi authorship pattern is expanding slowly in Indian oncology research.

Table 4. Year Wise Degree of Collaboration

\begin{tabular}{ccccccccc}
\hline S.No. & Year & No of Articles & No. of Authors & SAP* & \% & MAP* & \% & DC \\
\hline 1 & 2005 & 349 & 1179 & 20 & 0.19 & 329 & 3.11 & 0.03 \\
2 & 2006 & 397 & 1473 & 28 & 0.26 & 369 & 3.49 & 0.03 \\
3 & 2007 & 580 & 2004 & 32 & 0.30 & 548 & 5.18 & 0.05 \\
4 & 2008 & 592 & 1925 & 49 & 0.46 & 543 & 5.14 & 0.05 \\
5 & 2009 & 813 & 2515 & 37 & 0.35 & 776 & 7.34 & 0.07 \\
6 & 2010 & 978 & 3245 & 50 & 0.47 & 928 & 8.78 & 0.09 \\
7 & 2011 & 1080 & 3578 & 84 & 0.79 & 996 & 9.42 & 0.09 \\
8 & 2012 & 1116 & 4112 & 69 & 0.65 & 1047 & 9.90 & 0.10 \\
9 & 2013 & 1276 & 4471 & 45 & 0.43 & 1231 & 11.64 & 0.12 \\
10 & 2014 & 1569 & 5752 & 96 & 0.91 & 1473 & 13.93 & 0.14 \\
11 & 2015 & 1824 & 6349 & 85 & 0.80 & 1739 & 16.45 & 0.16 \\
\hline & \multirow{2}{*}{ Total } & 10574 & 36603 & 595 & \multirow{2}{*}{5.63} & 9979 & 94.37 & 0.09 \\
\end{tabular}

${ }^{*} \mathrm{SAP}=$ Single Authored Paper, ${ }^{*} \mathrm{MAP}=$ Multi Authored Papers, ${ }^{*} \mathrm{DC}=$ Degree of Collaboration

\section{TIME SERIES ANALYSIS}

Table 5. Time Series Analysis

\begin{tabular}{cccccccccc}
\hline S.No. & Year & $\mathbf{S A P}(\mathbf{Y})$ & $\mathbf{X}$ & $\mathbf{X}^{\mathbf{2}}$ & $\mathbf{X Y}$ & $\mathbf{M A P}(\mathbf{Y})$ & $\mathbf{X Y}$ & $\mathbf{C P}(\mathbf{Y})$ & $\mathbf{X Y}$ \\
\hline 1. & 2005 & 20 & -5 & 25 & -100 & 329 & -1645 & 349 & -1745 \\
2. & 2006 & 28 & -4 & 16 & -112 & 369 & -1476 & 397 & -1588 \\
3. & 2007 & 32 & -3 & 9 & -96 & 548 & -1644 & 580 & -1740 \\
4. & 2008 & 49 & -2 & 4 & -98 & 543 & -1086 & 592 & -1184 \\
5. & 2009 & 37 & -1 & 1 & -37 & 776 & -776 & 813 & -813 \\
6. & 2010 & 50 & 0 & 0 & 0 & 928 & 0 & 978 & $\mathbf{0}$ \\
7. & 2011 & 84 & 1 & 1 & 84 & 996 & 996 & 1080 & 1080 \\
8. & 2012 & 69 & 2 & 4 & 138 & 1047 & 2094 & 1116 & 2232 \\
9. & 2013 & 45 & 3 & 9 & 135 & 1231 & 3693 & 1276 & 3828
\end{tabular}




\begin{tabular}{cccccccccc}
10. & 2014 & 96 & 4 & 16 & 384 & 1473 & 5892 & 1569 & 6276 \\
11. & 2015 & 85 & 5 & 25 & 425 & 1739 & 8695 & 1824 & 9120 \\
\hline & Total & 595 & 0 & 110 & 723 & 9979 & 14743 & 10574 & 15466 \\
\hline
\end{tabular}

*SAP = Single Authored Paper, ${ }^{*} \mathrm{MAP}=$ Multi Authored Papers, ${ }^{*} \mathrm{CP}=$ Collaborative Papers (Y)

\section{SINGLE AUTHORED PUBLICATIONS: TIME SERIES ANALYSIS}

Straight line equation is applied to arrive at projections for future growth under Time Series analysis. Straight Line equation $\mathrm{Yc}=\mathrm{a}+\mathrm{bX}$ since $\Sigma \mathrm{x}=$ $0, a=\Sigma Y / N, \Sigma Y=($ Total Number of Paper by Single Author), $\mathrm{N}=$ (Number of Years), $\mathrm{a}=595 / 11, \mathrm{a}=$

$54.09, \mathrm{~b}=\Sigma \mathrm{XY} / \Sigma, \Sigma \mathrm{XY}=($ Total of XY Tables),$\Sigma=$ (Total of X2 Table), $b=723 / 110, b=6.57$.

Estimated literature in 2020 is, When $\mathrm{X}=$ 2020-2010(Mid-Year), $X=10$,

Apply Straight line equation, $\mathrm{Yc}=\mathrm{a}+\mathrm{bX}$ since

$\Sigma \mathrm{X}=0, \mathrm{Yc}=54.09+6.57 * 10, \mathrm{Y}$

$\mathrm{c}=54.09+65.7$,

Yc $=119.79$

\section{MULTI AUTHORED PUBLICATIONS: TIME SERIES ANALYSIS}

Straight Line equation $\mathrm{Yc}=\mathrm{a}+\mathrm{bX}$ since $\Sigma \mathrm{x}=$ $0, a=\Sigma \mathrm{Y} / \mathrm{N}, \Sigma \mathrm{Y}=($ Total Number of Paper by Multi Author), $\mathrm{N}=$ (Number of Years), $\mathrm{a}=9979 / 11, \mathrm{a}=$

907.18, $\mathrm{b}=\Sigma \mathrm{XY} / \Sigma, \Sigma \mathrm{XY}=$ (Total of XY Tables),$\Sigma=$ (Total of X2 Table), $b=14743 / 110, b=134.02$.

Estimated literature in 2020 is, When $\mathrm{X}=$ 2020-2010(Mid-Year) X = 10,

Apply Straight line equation, $\mathrm{Yc}=\mathrm{a}+\mathrm{bX}$ since

$\Sigma \mathrm{X}=0, \mathrm{Yc}=907.18+134.02 * 10, \mathrm{Yc}=907.18+1340.2$,

Yc $=2247.38$

\section{COLLABORATIVE PUBLICATIONS: TIME SERIES ANALYSIS}

Straight Line equation $\mathrm{Yc}=\mathrm{a}+\mathrm{bX}$ since $\Sigma \mathrm{x}=$ $0, a=\Sigma \mathrm{Y} / \mathrm{N}, \Sigma \mathrm{Y}=($ Total Number of Paper by Multi Author), $\mathrm{N}=$ (Number of Years), $\mathrm{a}=10574 / 11, \mathrm{a}=$

961.27, $\mathrm{b}=\Sigma \mathrm{XY} / \Sigma, \Sigma \mathrm{XY}=$ (Total of XY Tables), $\Sigma=$ (Total of X2 Table), $b=15466 / 110, b=140.6$.

Estimated literature in 2020 is, When $\mathrm{X}=$ 2020-2010(Mid-Year) X = 10,

Apply Straight line equation, $\mathrm{Yc}=\mathrm{a}+\mathrm{bX}$ since

$\Sigma \mathrm{x}=0, \mathrm{Yc}=961.27+140.6 * 10, \mathrm{Yc}=961.27+1406$,
Yc $=2367.27$

On the utilization of the formula of Time Series Analysis for the expectation of oncology research output in India for the year 2020, it was found that the future trend and development in oncology research literature output may take an expanding trend in single authored publications (Yc =93.51)during the years to come and collaborative publications trends also increasing gradually ( $\mathrm{Yc}=$ 2367.27).

\section{CONCLUSION}

In this study directs an authorship patterns towards collaborative research is seen reliable during 2005-2015 in the field of oncologyresearch output in India.The study exposes the following conclusions.

$\checkmark$ The increased trend towards multiple authorship is predominant as compare to single authorship in case of oncology in India.In the study, the degree of collaboration was not a constant value, it reveals varies of 0.03 to 0.16 percent and the mean quality as 0.09 .

$\checkmark$ The analysis found that single author papers maintained a low profile among oncology research scientists and the multi authorship pattern is expanding slowly in Indian oncology research.

Time Series Analysis for the expectation of oncology research output in India for the year 2020, it was found that the future trend and development in oncology research literature output may take a positive growth trend.

\section{REFERENCES}

Sudhier, K.G., and Librarian, P. (2007). Authorship patterns in physics literature: An informetric study on citations in doctoral theses of the Indian Institute of Science. Annals Library Informat Stud, 54: 90-94.

Elango, B., and Rajendran, P. (2012). Authorship Trends and Collaboration Pattern in the Marine Sciences Literature : A Scientometric Study. Internat J Informat Disseminat Technol, 2(3): 166-169.

Andras Pinter. (2013). Changing trends in authorship patterns in the JPS: Publish or 
perish. Journal of Pediatric Surgery, 48(2): 412417.

Pallab Pradhan, (2013). Authorship Pattern and Degree of Collaboration in Information Technology. J Computer Sci Informat Technol, 1(1): 46-54.

Goyal, V., G.K. Gupta, A. Kumar, M. Ambala and M. Ambala, (2013). Authorship Patterns and Collaborative Research. Trends in the Field of Chem Sci, 3(3): 184-186.

Bales, M.E., D.C., Dine, J.A., Merrill, S.B., Johnson, S., Bakken and C. Weng, (2014). Associating coauthorship patterns with publications in highimpact journals. J Biomed Informat, 52, 311318.

Navaneethakrishnan, S. (2014). Authorship patterns and degree of collaboration of Sri Lankan scientific publications in Social sciences and Humanities - A picture from SCOPUS. Library Philosophy and Practice, 2014(1).
Kapoor, N., M.V., Abola, A.B., Jena, and S.E. Smith, (2015). Trends in Authorship Patterns in HighImpact Radiology Publications, 1980-2013. Academic Radiology, 22(12), 1587-1591.

Velmurugan, C., and N. Radhakrishnan, (2015). Scientometric observations of Authorship Trends and Collaborative Research on DESIDOC Journal of Library and Information Technology. Collnet J Scientometrics Informat Management, 9(2): 193-204.

Koseoglu, M.A. (2016). Growth and structure of authorship and co-authorship network in the strategic management realm: Evidence from the Strategic Management Journal. BRQ Busin Res Quart, 1-18.

Senthilkumar, R., and M. Muthukrishnan, (2016). Scientometric analysis of the journal "pediatric blood and cancer" during 2005 - 2015, Internat J LibrarySci Res (IJLSR), 6(3): 17-26. 